\title{
The Effect of Combined Method of Chemical Disinfection and Gargling with Chlorhexidinetowards the Amount of Candida Albicans
}

\author{
Putri Welda Utami Ritonga, Haslinda Zainuddin Tamin, Dwi Suryanto
}

\begin{abstract}
Denture wearerusuallycareonly aboutthe denture hygiene and ignored the oral hygiene. The oral and denture hygiene can be maintainby using the combination of mouthwash and denture disinfections. Nowadays, microwave can be used as an alternative for denture disinfections and can be found in most household. Chlorhexidine has dual role, which are as the denture disinfectants and as the mouthwash. The aim of the study are to determine the influences of denture disinfectionsby using an 800 watts microwave in 3 minutes and 0,2\% chlorhexidine solution in 5 minutes along with gargling using 0,2\% chlorhexidine solution in 1 minute towards the amount of Candida albicans on the heat polimerization acrylic resin of the full denture wearer. This study is a clinical experiment and the subjects were selected according the inclusion criteria. The total number of subjects are 18 person and were divided into 3 groups. Subjects were done a swab on the palate and the intaglio surface of the denture, then the swab were incubated and the number of Candida albicans were counted. One way Anova test shows the effects of denture disinfection using microwave and garglingusing chlorhexidine ( $p=$ 0,0001), and dentures disinfection with chlorhexidine solution and gargling using chlorhexidine solution $(p=0,008$ and $p=0,014)$ towards the amount of Candida albicans. Tukey test shows different effects between those group towards the amount of Candida albicans ( $p=0,007)$. In conclusion, denture disinfections aloneis not enough to eliminates the Candida albicanspathogen, but mustbe combined with the oral cavity care. Denture disinfections with microwave and gargling using chlorhexidinesolution are more effective to prevent denture stomatitis.
\end{abstract}

Keywords: acrylic resin, microwave, chlorhexidine, Candida albicans

\section{Introduction}

There are a lot of normal microflora that plays an active role in maintaining oral health and prevent colonization of exogenous microorganisms in the oral cavity. The most dominant group of yeast is Candida albicans which is a normal commensal organism in oral cavity. ${ }^{1}$ The loss of teeth will cause changes in anatomic and functional which result in

physiological trauma. The loss of the teeth can be overcome withthe replacement of full denture. ${ }^{2}$ The dentist will give instructions to the patient about how, frequency and time to clean the denture, releasing the denture at night, and maintaining the oral cavity health whenusing the denture in order to prevent inflamation such as denture stomatitis after the denture's fitting..$^{3}$

There are many way of denture disinfections such as, mechanically, chemically, and combination. One of the new chemically disinfections is to put the denture in a non-metal container, containing distilled water and put it in the microwave for a few minutes. Nowadays, microwave is no longer a luxury item because most household posses it, especially in Medan, the most distribution of microwave is the high-power (800-900 watts). Disinfections using a microwave is a good method because it can kill microorganisms like Stafilococcus aureus, Stafilococcus epidermis, Klebsiella pneumonia, Streptococcus gordonii and Candida albicans, does not increase C.albicans resistance, does not change the smell and colour, and does not cause allergic reactions. ${ }^{4}$

Chlorhexidine is a broad spectrum antiseptic that can kill some microorganisms, including C. albicans. Chlorhexidine is widely used as denture disinfections, mouthwash, gingivitis treatment, antiseptic solution after minor oral surgery, oral candidiasis treatment, and for the inflamation caused by irritation of the denture. Full denture wearer must not only maintaining the denture hygiene, but also the oral hygiene, because the cleanliness of both will affect each other. Patient's oral hygiene can be maintained and preserved using the antiseptic mouthwash, combined with denture disinfectionsto get an adequate denture and oral cavity hygiene. ${ }^{6}$ The aim of the study are to determine the effects of denture disinfections with 800 watts microwave for 3 minutes, $0,2 \%$ chlorhexidine solution in 5 minutes along with garlingusing $0,2 \%$ chlorhexidine solution for 1 minute towards the amount of C.albicans in the heat polimerization acrylic resin of the full denture wearer.

\section{Materials and methods}

The subjects in this study are patients with denture made in Rumah Sakit Gigi dan Mulut Pendidikan Faculty of Dentistry University of North Sumatera. The inclusion criteria are subjects aged 45-75 years old, 
using full dentures in upper and lower jaw, have no systemic diseases, does not cleaned the dentures and oral cavity in particular, the dentures have an adequate retention and stabilization, and normal saliva acidity. ${ }^{7}$ Before participating, subjects were asked to read and fill in the ethical clearance and informed consent form. Subjects were instructed not to eat or drink for 2 hours before measuring the salivary $\mathrm{pH}$. The study was divided into two periods, the first period is one week before the experiment for calibration purpose and the second period is the experiment period. ${ }^{8}$ Subjects were divided into 3 groups, each subjects were not given the actual treatments, but only by education and instruction about cleaning the dentures and oral cavity. On the first day of the first period, by using a cotton bud, swab was done on the palate surface and the intaglio surface of the denture (Figure 1). Swab was done within 30 seconds with a dimension of $1 \times 1 \mathrm{~cm}$ on the anterior, right, left and posterior area. $^{8}$
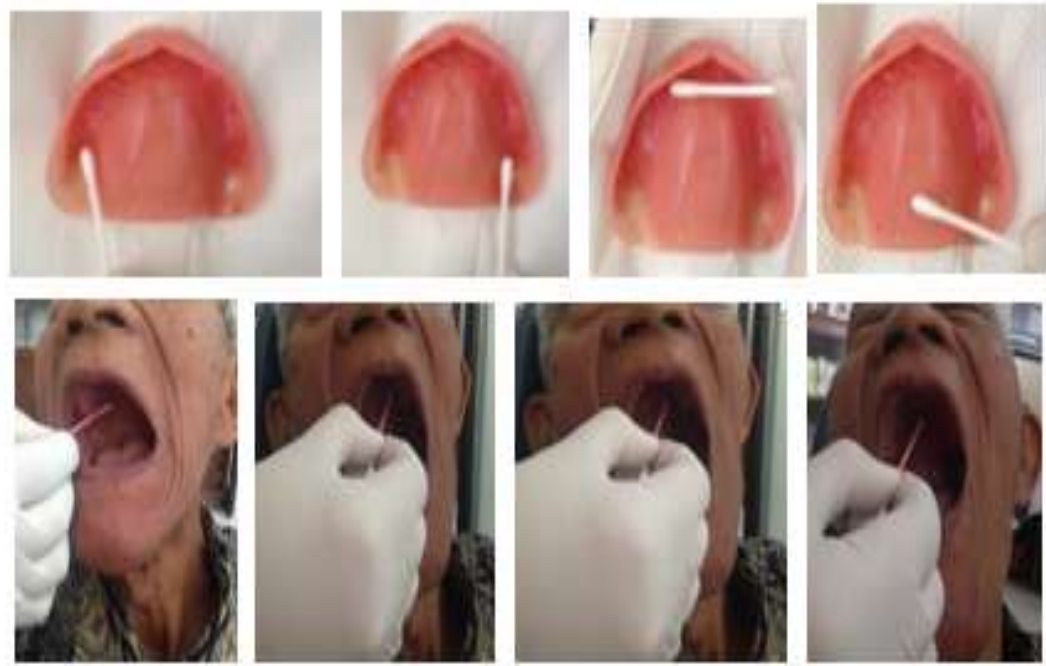

Figure 1. Swab in the intaglio surface of the denture and palatum surface of the mouth

Results obtained from the swab is placed into $10 \mathrm{ml}$ Phosphate buffered saline and vibrated with vortex. Furthermore, seeding is done on Potato Dextrose Agar (PDA), incubated for 48 hours at $37^{\circ} \mathrm{C}$ temperature, then Candida albicans were counted with the units of $\mathrm{CFU} / \mathrm{ml}$ in $100 \mathrm{~mm}^{3}$ using a colony counter (Figure 2).

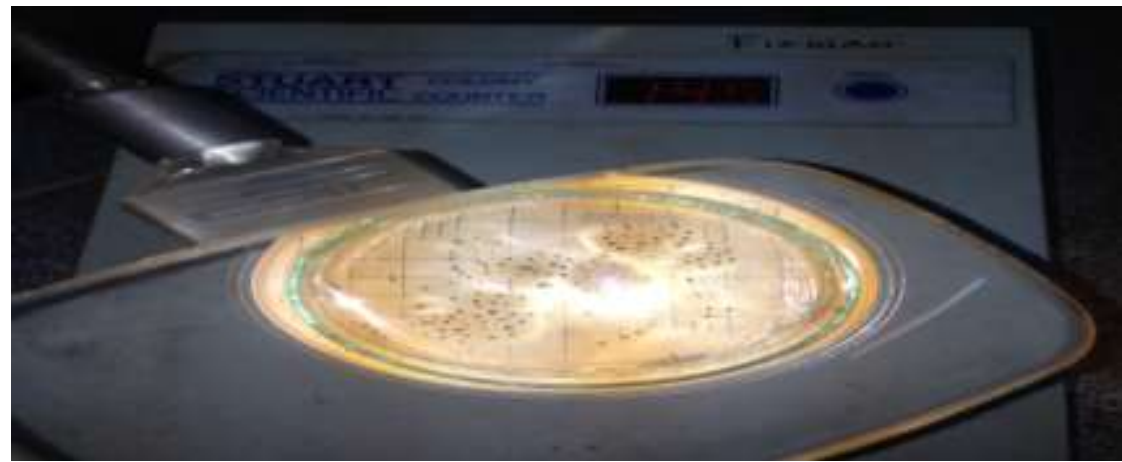

Figure 2. Candida albicans counting using colony counter

On the 7th day on the first period, swab is done in the same way such as on the first day. After the first period is completed, experiment continued with the second period. Subjects that have been divided into 3 groups in the first period, remain in 3 groups in the second period but with the different treatment. Group A is the control group (denture were soaked into water and patients gargle using water), in group B patients gargle using chlorhexidine solution and the dentures were disinfected with microwave energy, in group C patients gargle using chlorhexidine solution and the dentures were disinfected with chlorhexidine solution as well. Before conducted the second period, all the denture were disinfected with ultrasonic cleanser. In the first day, swab is done to all the subject in group A, B, and C the same way with the first period. The results of the incubated swabin palatum and intaglio surface of the dentures were calculated and considered as the data for CPU (after), 


\begin{tabular}{|c|c|c|c|}
\hline Group & $\mathrm{n}$ & $\mathrm{X} \pm \mathrm{SD}$ & $\mathrm{p}$ \\
\hline $\mathrm{A}(1)$ & \multirow[t]{6}{*}{6} & $1,62 \pm 8,17$ & \multirow{3}{*}{0,55} \\
\hline $\mathrm{A}(2)$ & & $0,24 \pm 1,80$ & \\
\hline $\mathrm{A}(3)$ & & $-1,58 \pm 2,29$ & \\
\hline $\mathrm{A}(4)$ & & $-2,74 \pm 9,03$ & \multirow[t]{3}{*}{0,54} \\
\hline $\mathrm{A}(5)$ & & $0,04 \pm 0,89$ & \\
\hline $\mathrm{A}(6)$ & & $0,53 \pm 2,46$ & \\
\hline $\mathrm{B}(1)$ & \multirow[t]{6}{*}{6} & $-19,94 \pm 7,15$ & \multirow[t]{3}{*}{$0,0001^{*}$} \\
\hline $\mathrm{B}(2)$ & & $-43,8 \pm 17,63$ & \\
\hline $\mathrm{B}(3)$ & & $-82,75 \pm 7,84$ & \\
\hline $\mathrm{B}(4)$ & & $-22,77 \pm 9,95$ & \multirow[t]{3}{*}{$0,0001^{*}$} \\
\hline $\mathrm{B}(5)$ & & $-49,23 \pm 16,43$ & \\
\hline $\mathrm{B}(6)$ & & $84,98 \pm 9,48$ & \\
\hline $\mathrm{C}(1)$ & \multirow[t]{6}{*}{6} & $4,80 \pm 56,33$ & \multirow[t]{3}{*}{$0,008^{*}$} \\
\hline $\mathrm{C}(2)$ & & $-23,72 \pm 9,90$ & \\
\hline $\mathrm{C}(3)$ & & $-42,71 \pm 10,22$ & \\
\hline $\mathrm{C}(4)$ & & $0,62 \pm 35,93$ & \multirow[t]{3}{*}{$0,014 *$} \\
\hline $\mathrm{C}(5)$ & & $-27,72 \pm 11,29$ & \\
\hline $\mathrm{C}(6)$ & & $-43,87 \pm 12,55$ & \\
\hline
\end{tabular}

the total of Candida albicans on the seventh day of the first period considered as the data for the CPU (before) then the data will be inserted into the formula. Swab is repeated on the fourth and seventh day. The total of Candida albicans from the swab in palatum/ intaglio surface of the upper denture for the A,B,and C group in the fourth day is the data for CPU (after), and Candida albicans total on the first day of second period is the CPU data (before) and were inserted into the formula. Candida albicans count results from the swab in palate/intaglio surface of the upper denture on the seventh day of $\mathrm{A}, \mathrm{B}$, and $\mathrm{C}$ group considered as the after data for the CPU, and Candida albicans count results on the fourth day of the second period considered as the before data for CPU and were inserted into the formula: ${ }^{11}$

$\frac{\mathrm{CFU} \text { (after) }-\mathrm{CFU} \text { (before) }}{\mathrm{CFU} \text { (before) }} \times 100$

\section{Explanation:}

CFU (before) : The total of C.albicansobtained from the incubation of swab on the palate/ intaglio surface ofthe denture on the seventh day of the first period and the first and fourth day of the second periodCFU (after) : The total of C.albicansobtained from the incubation of swab on palate/intaglio surface of the denture on thefirst day of the second period and the fourth dan seventh day of the second period

\section{Results}

The result from one way Anova test shows that there are no difference between the swab on the palatum surface and intaglio surface of the denture in group A with the value of $p=0,55$ for the swab in palatum surface and 0,54 for the swab in intaglio surface of the denture whereas group B shows a significant difference with the value $\mathrm{p}=0,0001$ for the both swab. $\mathrm{C}$ groups show a significant difference with the value of $\mathrm{p}=0,008$ for the swab in palatum surface and $p=0,014$ for the swab in intaglio surface of the denture, therefore there is an effect in denture disinfection using microwave and chlorhexidine solution, and rinsing with chlorhexidine solution towards the amount of Candida albicans (Table 1).

Table 1. The result of Group A,B and C using one way Anova test *significant difference

\begin{tabular}{|c|c|c|}
\hline \multicolumn{2}{|c|}{ Group } & $\mathrm{p}$ \\
\hline B1 & C1 & 0,19 \\
\hline B2 & C2 & 0,40 \\
\hline B3 & C3 & $0,007^{*}$ \\
\hline B4 & C4 & 0,26 \\
\hline B5 & C5 & 0,35 \\
\hline B6 & C6 & $0,007^{*}$ \\
\hline
\end{tabular}


The result of Tukey test shows significant difference between group B and C, between groups B(3) and $\mathrm{C}(3)(\mathrm{p}=0,007)$ and between group $\mathrm{B}(6)$ and $\mathrm{C}(6)(\mathrm{p}=007)$ (Table 2).

Table 2. The difference effect between group B and C using Tukey test *significant difference

\section{Discussion}

Recently, disinfection method by using microwave is said to be an useful alternative for other chemical disinfectants. Microwave is categorized as a chemical disinfection method for dentures because of the chemical reaction which occurrs at polar molecule in the microorganisms which colonised on the dentures, from microwave disinfection. Microwave is used as an alternative to clean the dentures because microwave energy does not change the smell and colour of the dentures, doesn't create allergic reaction to the user, and doesn't have any expiration date. Besides that, microwave also can kill some microorganisms, such as Candida albicans so it can also be counted as one of denture stomatitis treatments. Lately, almost all households have microwave as a cooking-and-heating-food equipment, therefore, microwave can also be utilized as one of the methods to disinfect dentures. Neppelenbroek et al (2008) stated that the effect that can kill the microorganisms is the thermal effect resulted from microwave. In the microwave, microwave is resulted from an electron tank called magnetron. The microwave then will be reflected by a layer of metal in the microwave and absorbed by materials containing water and fat, so the molecules of the material vibrate and produce friction which creates heat. Living cells have water in them, so it can be concluded that living cells are susceptible to microwave. Neppelenbroek et all (2008) quoted Baena-Monroy et all that microorganism can be killed at a lower temperature. This is because of the electromagnetic interaction with molecule cells and liquid around them creates the effect that is not affected by thermal (non thermal effect). Other than that, microorganism also has high intracellular concentration of ion, which can absorb thermal much more than the liquid around it. Mechanical disruption process happens when the electromagnetic wave moves the cell's molecule in high speed so it can pass through the elastic border of the cell wall, resulting in the rupture of cells. That causes higher significance in microwave disinfection and rinsing with chlorhexidine compared with only rinsing with chlorhexidine with the number of Candida albicans.

Kassab (2009) used sodium hypochlorite $0,5 \%$, chlorhexidine $0,2 \%$, and microwave in 650 watt for 6 minute to disinfect 32 heat-polymerized-acrylic samples. These three substances are significantly effective in killingCandida albicans, but chlorhexidine is proved to be the most effective. The difference in result of this study with the study by Kassab is because the power of the microwave used in disinfecting dentures in this study is higher than used in Kassab's. The higher the power of the microwave the faster the process of disinfection. Microorganism has thermal properties which directly related to ruptures of cells. Microorganisms can absorb the heat from microwave in a higher level than liquid around them. Microwave heating is conversion energy, not heat as in conventional oven, therefore microwave absorbance material is exposed to microwave which will change this energy into heat in it. Attwa et al (2012) stated that the power of microwave, exposing time, type of microorganisms colonized the denture and intensity of disinfection with microwave are related to the decreasing number or microorganisms.

Chlorhexidine has fungicidal and fungistatic effect which will cause coagulation of nucleoprotein and affect the cell wall and cause the cytoplasm to diffuse through the plasma membrane. Gade et al (2011) stated that the use of $0,2 \%$ chlorhexidine as a mouth rinse and denture disinfection for 2 weeks, gives a significant effect on 35 full dentures users with denture stomatitis. Gade et all also stated that the use of chlorhexidine only as mouth rinse, will not affect the clinical condition of palatal mucosa of denture stomatitis patient. Treating it only by orally will not kill Candida albicans effectively, because Candida albicans is still located on the intaglio surface of dentures, thereforeCandida albicans can cause continuous infection.

Oral health depends on the integrity of mucosa that acts as a barrier to prevent the penetration of microorganisms, so adequate maintenance of oral health must be done either by dentures users or nonedentulous individuals. C.albicans is an opportunistic microorganism on human body because on certain condition $\mathrm{C}$. albicans can cause infection and tissue breakdown.

Conclusion of this study is oral and denture cleansing must be done thoroughly and continuously on full dentures. Dentures disinfection without oral maintenance won't be enough to eliminate pathogenic Candida albicans which can cause denture stomatitis, therefore it must always be combined with oral maintenance such as rinsing with antiseptic solution. Disinfection with microwave 800 watt for 3 minutes and rinsing with $0,2 \%$ chlorhexidine solution for 1 minute is more effective than disinfection with chlorhexidine solution for 5 minute and rinsing with $0,2 \%$ chlorhexidine solution for 1 minute.

\section{Affiliation}

1. Putri Welda Utami Ritonga, DDS., MDSc., Sp.Pros, Lecture, Department of Prosthodontics, Faculty of Dentistry, University of Sumatera Utara, Medan 
2. Prof. Haslinda Zainuddin Tamin, DDS., M.Kes., Sp.Pros(K), Professor, Department of Prosthodonstics, Faculty of Dentistry, University of Sumatera Utara, Medan

3.Prof. Dwi Suryanto, MSc, Professor, Department of Microbiology, Faculty ofMathematics and Science, University of Sumatera Utara, Medan.

\section{References}

[1]. Afrina L. Prevalensi Denture Stomatitis Yang Disebabkan Kandida Albikans Pada Pasien Gigitiruan Penuh Rahang Atas Di Klinik Fakultas Kedokteran Gigi Universitas Sumatera Utara.Skripsi; 2007.

[2]. KhindriaSK. Evolution of Denture Base Material.J Indian Prost Soc. 2009 Aug:9(2):64-9.

[3]. Pattanaik S, Vikas BVJ, Pattanaik B, Sahu S, Lodam S. Denture Stomatitis: Literature Review.J of Indian Academy of Oral Medicine and Radiology. 2010 Jul;22(3):136-40.

[4]. Neppelenbroek KH, Pavarina AC, Spolidorio DMP, Massucato EMS, Spolidorio LC,\& Vergani CE.Effectiveness of Microwave Disinfection of Complete Dentures on The Treatment of Candida Related Denture stomatitis.J Oral Rehab 2008;35: 836-46.

[5]. Cenci TP, Delbelcury AA, Crielard W, \& Tencale JM. Development of Candida-Associated Denture Stomatitis: New Insights.J Appl Oral Sci. 2008 Feb;16(2):86-94

[6]. Uludamar A, Ozkan YK, Kadir T, Ceytan I. In vivo efficacy of alkaline peroxide tablets and mouthwashes on Candida albicans in patients with denture stomatitis.J Appl Oral Sci. 2010May;18(3):291-6.

[7]. Bhat V dkk. Prevalance of Candida associated denture stomatitis (CADS) and spesification of Candida among complete denture wearers of south west coastal region of karnataka. NUJHS.2013 Sept:3(3):59-63.

[8]. Chetan MD, Azhagarasan NS, Miglani S, Mohammed HS, Prasad AH.Microbiological evaluation of the effectiveness of commercially available denture cleansing agents. Int. J. Drug Dev. \& Res.2011 Jun;3(3):159-72.

[9]. Campanha NH dkk.Cell membrane integrity of candida albicans after different protocols of microwave irradiation. American $\mathrm{J}$ of Infectious Diseases and Microbiology.2013 May;1(3):38-45.

[10]. Attwa AM, Al-Akhali AM, Farahatmtwaly A,Taha A. Effect of the microwave irradiation on disinfection of complete denturelined with soft resilient liner.Indian Journal of Dentistry. 2012Jul;3(3):145-9.

[11]. Gade A dkk. Comparison of Oral hygiene and Denture Practice and Awareness.Pakistan Oral \& Dental Journal. 2012 Dec;32(3):469-74.

[12]. Kassab NH, Mustafa EA, \&Hasan RH. Antifungal Effect: Comparison of Commercial Denture Cleansers and Microwave Energy.Al-Rafidain Dent J. 2009;9(1):24-31. 